Superalloys 2012: $12^{\text {th }}$ International Symposium on Superalloys

\title{
PHYSICS-BASED MODELING OF THERMO-MECHANICAL FATIGUE IN PWA 1484
}

\author{
Robert L. Amaro ${ }^{1}$, Stephen D. Antolovich* ${ }^{1,2}$, Richard W. Neu ${ }^{1,2}$, Alexander Staroselsky ${ }^{3}$ \\ ${ }^{1}$ George W. Woodruff School of Mechanical Engineering and Mechanical Properties Research Laboratory, Georgia Institute of \\ Technology, 801 Ferst Dr. Atlanta, Georgia,30332, USA
}

\begin{abstract}
${ }^{2}$ School of Materials Science and Engineering and Mechanical Properties Research Laboratory, Georgia Institute of Technology, 771 Ferst Dr, Atlanta, Georgia, 30332, USA
\end{abstract}

${ }^{3}$ Pratt \& Whittney, 400 Main St. East Hartford CT, 06108, USA

Keywords: superalloy, crack initiation, microstructure, environmental fatigue

\begin{abstract}
Thermomechanical fatigue (TMF) is a common damage process incurred by superalloys used for turbine components. Life modeling of TMF in superalloys has traditionally looked to phenomenological approaches for coupling the environmentalfatigue interactions occurring during TMF loading. While these approaches provide good predictive results within the range of test variables studied, they are not easily extrapolated to other conditions. A life model has been developed for single crystal Nibase superalloys experiencing out-of-phase (OP) TMF which explicitly couples the interactions between the dominant damage mechanisms and the base material evolution affecting inelastic deformation. This paper concentrates on the fundamental physics of the deformation and damage processes which are the foundation for the model. This study represents a fundamental experimental/analytical/numerical approach to life prediction under complex loading and thermal conditions. It integrates detailed dislocation substructure development, microstructural evolution, oxidation, constitutive behavior, solid mechanics and numerical modeling; resulting in very accurate and robust TMF life prediction capability.
\end{abstract}

\section{Introduction}

Thermomechanical fatigue (TMF) is a damage process commonly incurred by turbo machinery under normal operating conditions. Thermomechanical fatigue couples both thermal and mechanical fatigue, and can occur at both (relatively) short and (relatively) long time scales. As the primary life-limiting process occurring in turbines, life prediction models which account for not only the independent damage drivers occurring but also the interactions between the primary damage drivers are key to increasing turbine life and operating temperatures, thereby reducing cost and emissions, respectively. Nickel-base superalloys are commonly used in turbines due to their relative stability when mechanically loaded at temperatures up to $85 \%$ of their melting temperature and resistance to environmental degradation [1]. Considerable research has been performed on the crack initiation of superalloys experiencing TMF. The models include damage summation, critical plane theories [2,3], micromechanics approaches [4] and cumulative damage models [5-7], among others. While these models predict TMF lives reasonably well for the limited range of loads and temperatures for which they were developed, there is still a need for predictive models which explicitly link the lower temperature deformation and the higher temperature material degradation when predicting TMF life. TMF testing, purpose and benefits of multiple test types, and identification of the (macro) dominant damage mechanisms for this work were discussed elsewhere [8], while details of the model development were described in [9]. This paper concentrates on the microstructural aspects of the dominant damage mechanisms and their interactions occurring during OP TMF of single crystal Ni-base superalloy PWA 1484. Microstructural-specific aspects of the model derivation and the resulting improved model efficacy are highlighted.

\section{Material}

Material characterization tests were performed on the second generation single crystal superalloy PWA 1484 in the standard heat treat condition [10]. The material's microstructure is comprised of small, typically coherent, $\mathrm{Ni}_{3}(\mathrm{Al} / \mathrm{X}) \mathrm{L1}_{2}$ (FCC-like) precipitates $\left(\gamma^{\prime}\right)$, embedded in a nickel FCC matrix $(\gamma)$ which is a substitutional solid solution of $\mathrm{Ni}$ and other elements [11]. The material microstructure is shown in Fig. 1 while the nominal chemical composition is provided in Table 1 .

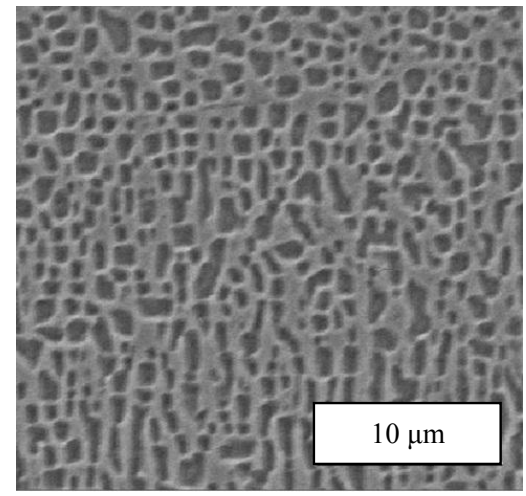

Figure 1: Microstructure of PWA 1484-

Table I: Nominal composition of PWA 1484 (wt \%) [10]

\begin{tabular}{|c|c|c|c|c|c|c|c|c|}
\hline $\mathrm{Al}$ & $\mathrm{Co}$ & $\mathrm{Cr}$ & $\mathrm{Mo}$ & $\mathrm{Re}$ & $\mathrm{Ta}$ & $\mathrm{W}$ & $\mathrm{Hf}$ & $\mathrm{Ni}$ \\
\hline 5.6 & 10 & 5 & 2 & 3 & 8.7 & 6 & 0.1 & Bal. \\
\hline
\end{tabular}

\section{Experimental Procedures and Results}

The philosophy, testing and analytical modeling methodology used during this study is provided in Fig. 2 . 


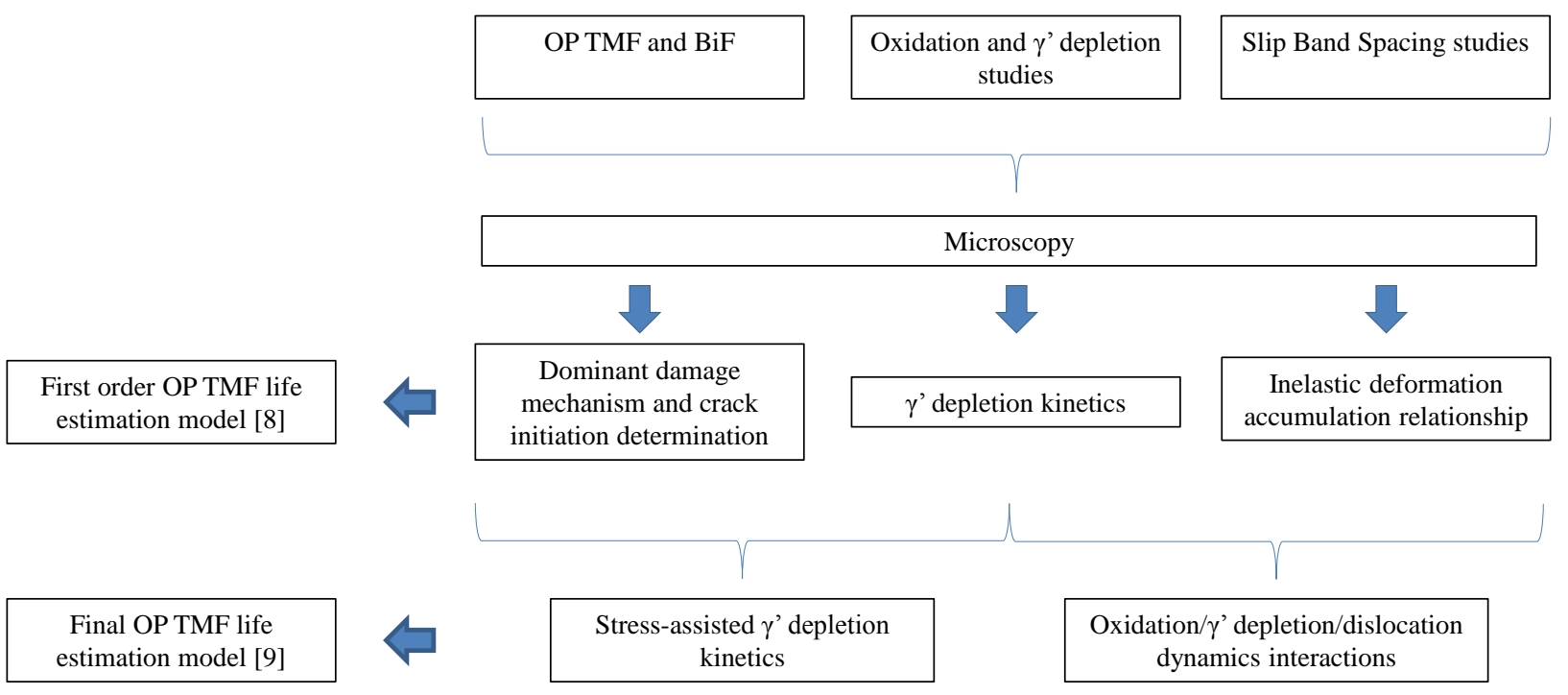

Figure 2: Experimental and analytical methodology for creation of physics-based crack initiation model

Figure 2 provides an overview of our philosophy and over-all approach taken during the execution of this work. Whereas a great deal of experimentation and analytical modeling went into the formulation of the final model, this paper focusses on the physical aspects of the experimental results.

The TMF conditions experienced by turbine components are typically simulated in the laboratory by in-phase (IP) or OP TMF tests. An IP TMF test is one in which the maximum temperature corresponds with the maximum applied load and the minimum temperature occurs at the minimum applied load. In this paper we us the term "load" in a general sense and within that context it may include strain as well. The maximum temperature in an OP TMF test, conversely, occurs at the minimum applied load while the minimum temperature corresponds to the maximum applied load. These two loading conditions are generally used as they provide bounds for life prediction, with creep-fatigue damage mechanisms primarily resulting from IP TMF and environmentalfatigue primarily resulting from OP TMF. The IP and OP TMF waveforms are shown in Fig. 3. The TMF waveforms shown in Fig. 3 consist of continuously varying temperatures and loads. As such the independent damage mechanisms occurring as a result of temperature and mechanical load also occur simultaneously. Decoupling of the interactions produced by the simultaneouslyoccurring mechanisms is difficult, and typically requires extensive testing.

Bithermal fatigue (BiF) tests have also been used to simulate TMF conditions [12-15]. The OP BiF test consists of heating to maximum temperature while maintaining zero stress, followed by an isothermal compressive load occurring at maximum temperature. The temperature change to minimum cycle temperature then occurs at zero stress, followed by an isothermal tensile load occurring at minimum temperature. The $\mathrm{OP} \mathrm{BiF}$ waveform is shown in Fig. 4.

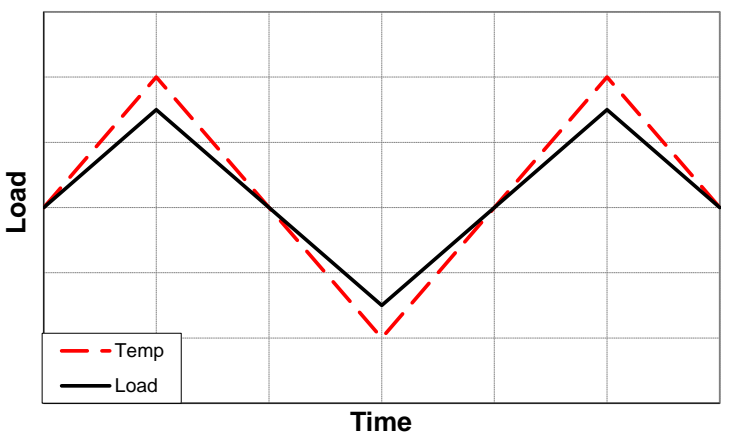

a)

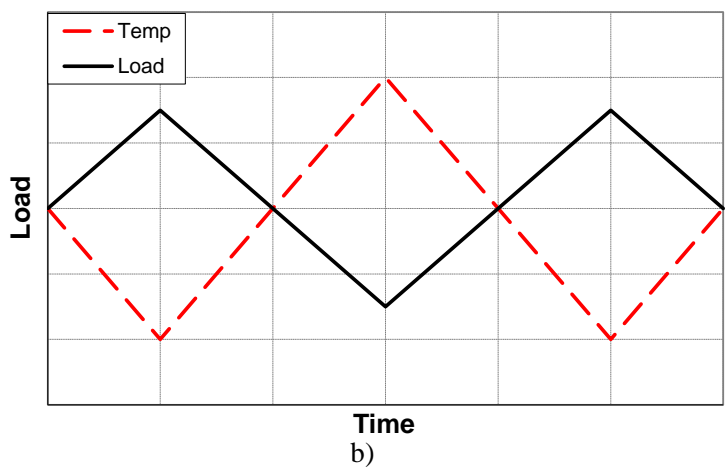

Figure 3: Temperature and strain TMF waveforms: a) in-phase, b) out-of-phase 


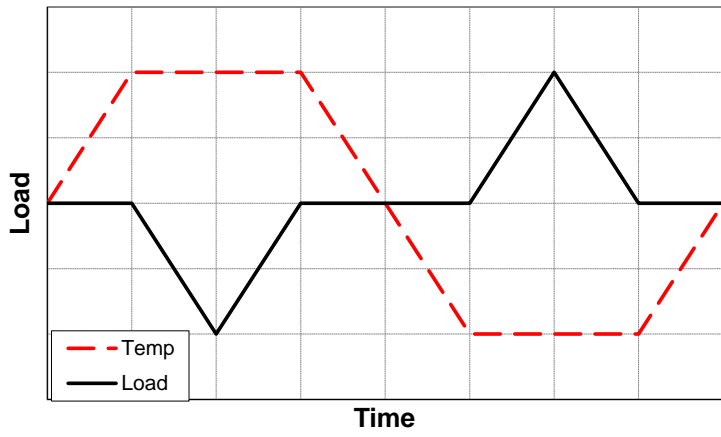

Figure 4: Out-of-phase BiF temperature and load waveforms

Due to the isothermal load excursions, the $\mathrm{OP} \mathrm{BiF}$ test effectively superimposes isothermal high-temperature damage mechanisms occurring in compression with isothermal low-temperature tensile damage mechanisms. As such the BiF test helps to decouple the interactions between the dominant damage mechanisms occurring during TMF conditions. Whereas a robust test matrix comprised of either test method (TMF or $\mathrm{BiF}$ ) may provide the required insight to the dominant damage mechanisms occurring in $\mathrm{OP}$ TMF as well as their interactions, the judicious use of both waveforms will provide detailed insight into damage mode interactions and require fewer tests.

In order to simulate the life-limiting operating conditions experienced by turbine blades, both OP TMF and OP BiF tests were performed on PWA 1484 specimens. Dog bone specimens were prepared per ASTM E606 [16] with a gage length of $12.7 \mathrm{~mm}$ and a gage diameter of $6.35 \mathrm{~mm}$. Testing was performed in the Mechanical Properties Research Laboratory at Georgia Institute of Technology. Full details of test procedures and equipment are provided in [17]. The test matrices were developed to induce all pertinent damage mechanisms, as well as to appropriately isolate the dominant damage mechanisms in order to elucidate the damage mechanism interactions. The majority of the $\mathrm{TMF}$ and $\mathrm{BiF}$ tests performed had a minimum temperature of $550^{\circ} \mathrm{C}$, a maximum temperature of $1050^{\circ} \mathrm{C}$ and a cycle time of 180 seconds. The fatigue test matrix and experimental results for this work are shown in Table 2.

The effective temperature (Teff) in the final column of Table 2 is an Arrhenius-averaged cycle temperature defined through the following equation:

$$
\exp \left(\frac{-Q}{R T_{e f f}}\right)=\frac{1}{\Delta t} \int_{t 1}^{t 2} \exp \left(\frac{-Q}{R T(t)}\right) d t
$$

where $Q$ is the activation energy for high-temperature material degradation ( $\gamma^{\prime}$ depletion in this case), $R$ is the universal gas constant, $T(t)$ is the absolute cycle temperature as a function of time for the portion of the cycle having temperatures above that which oxidation and $\gamma^{\prime}$ depletion processes occur. The activation energy for $\gamma^{\prime}$ depletion in PWA 1484 , between $850^{\circ} \mathrm{C}$ and $1050^{\circ} \mathrm{C}$, was determined to be $162.8 \mathrm{~kJ} / \mathrm{mol}$ [17] using an Arrhenius-type data analysis of $\gamma^{\prime}$ depletion results. This value is in line with those obtained from the literature for similar alloys $[18,19]$. The minimum activation temperature was chosen as $800^{\circ} \mathrm{C}$ based upon the results of the literature search [20-24], and the integration occurs over the cycle period between $800^{\circ} \mathrm{C}$ and the cycle maximum temperature $(\Delta t=t 1-t 2)$.

The results of the TMF and $\mathrm{BiF}$ tests are shown graphically in Figs. 5 and 6.

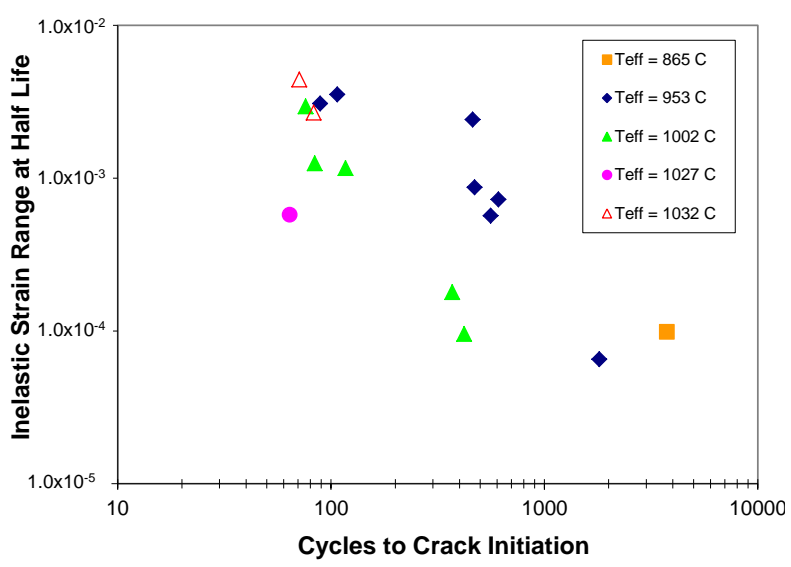

Figure 5: Results for TMF and BiF tests

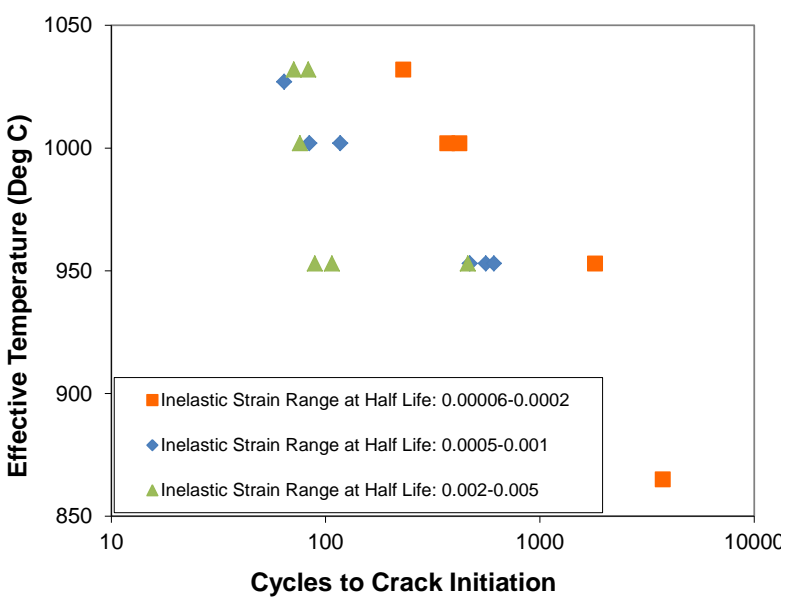

Figure 6: Results for TMF and $\mathrm{BiF}$ tests in terms of effective temperature

The mechanical test results indicate that there is an inverse relationship between both the inelastic strain range experienced by the specimen and the number of cycles to crack initiation as well as the cycle effective temperature and the number of cycles to crack initiation, though neither metric (alone) correlates the data well. A detailed discussion of the experimental procedure and results of all of the TMF and BiF tests is provided in [9].

\section{Model Derivation and Application}

A crack initiation life model for polycrystalline superalloys experiencing high temperature isothermal fatigue was proposed previously [25] and is modified in this work to take into account TMF cycling and the details of damage accumulation. The model presumes that a crack of critical size, $X_{x r i t}$, will have initiated when a critical number of slip bands, $N_{s}$, having spacing $C$ impinge upon an environmentally degraded region of the base material, such as an oxidized grain boundary or oxide spike. The relationship is described by: 
$X_{\text {crit }}=N_{S} C$

Given that the crack precursor, $X_{x r i t}$, occurs as a result of environmental degradation, it can be replaced by the per-cycle diffusion kinetics describing said degradation, $\gamma^{\prime}$ depletion in this case. Isothermal, non-stressed oxidation and $\gamma^{\prime}$ depletion experiments were conducted between $850^{\circ} \mathrm{C}$ and $1050^{\circ} \mathrm{C}$. The $\gamma$ ' depletion kinetics of PWA 1484 exhibit a classical power law relationship in the temperature range of interest [17]:

$X_{\gamma^{\prime}}^{0}=\operatorname{Aexp}\left(\frac{-Q_{\gamma^{\prime}}}{R T}\right) t^{n}$

where $X_{\gamma^{\prime}}^{0}$ is the non-stressed $\gamma^{\prime}$ depletion depth, $Q_{\gamma^{\prime}}$ is the effective activation energy, $n$ is a constant, $T$ is the absolute temperature and $R$ the universal gas constant. While the kinetics at $850^{\circ} \mathrm{C}$ were very nearly parabolic $(\mathrm{n}=0.5)$, the kinetics at $950^{\circ} \mathrm{C}$ and $1050^{\circ} \mathrm{C}$ were subparabolic $(\mathrm{n}<0.5)$. The material produced different oxides depending upon temperature and time of exposure. The oxides produced at $850^{\circ} \mathrm{C}$ were primarily composed of $\mathrm{Cr}_{2} \mathrm{O}_{3}, \mathrm{CoO}$, and $\mathrm{NiO}$; while the oxides produced at $1050^{\circ} \mathrm{C}$ were $\mathrm{Al}_{2} \mathrm{O}_{3}$ and $\mathrm{NiO}$ or $\mathrm{Al}_{2} \mathrm{O}_{3}$ and $\mathrm{NiO}$ interspersed with $\mathrm{NiAl}_{2} \mathrm{O}_{4}$ spinel. High temperature exposure at $950^{\circ} \mathrm{C}$ resulted in $\mathrm{CoO}$ and $\mathrm{NiO}$ in the dendritic regions and $\mathrm{NiO}, \mathrm{CoO}$ with small amounts of $\mathrm{Cr}_{2} \mathrm{O}_{3}$ and $\mathrm{Al}_{2} \mathrm{O}_{3}$ in the interdendritic regions. As the material produces a different stable oxide as a function of exposure temperature, and given that the oxidation kinetics for $\mathrm{Ni}$ base superalloys are intrinsically linked to the the $\gamma^{\prime}$ depletion kinetics via the diffusion of $\mathrm{Al}$, the resulting (calculated) activation energy must be understood to be an effective value for this temperature range. Of interest, the vast majority of the oxides produced on PWA 1484 experienced considerable spallation during cooling to room temperature. Given that the material would experience this temperature range at least once per day during normal operating conditions, the oxide spallation and subsequent effect on degradation kinetics must be taken into account during component design.

In order to characterize the low(er)-temperature tensile slip accumulation response of PWA 1484, monotonic and cyclic tests were performed at $21^{\circ} \mathrm{C}, 445^{\circ} \mathrm{C}, 545^{\circ} \mathrm{C}$ and $650^{\circ} \mathrm{C}$. Optical micrographs of specimens tested at $21^{\circ} \mathrm{C}$ and $650^{\circ} \mathrm{C}$ are shown in Figs. 7 and 8, respectively. Whereas low temperature deformation occurs with slip concentrated into relatively few slip bands, high(er) temperature deformation yields a more homogeneous deformation response.

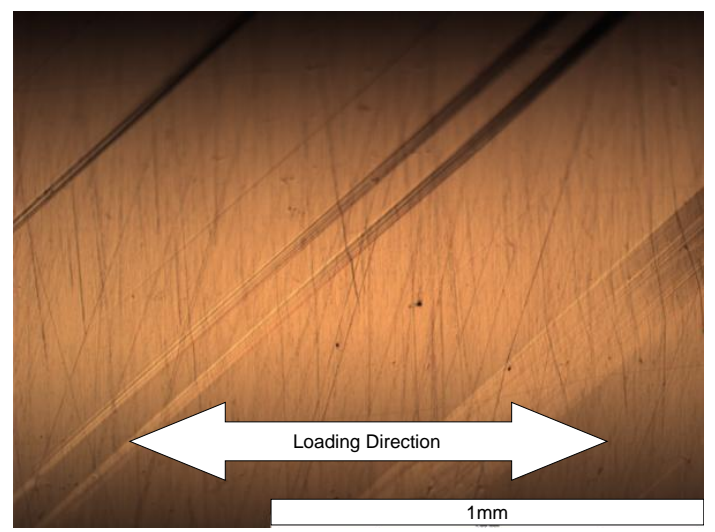

Figure 7: Slip bands intersecting surface of PWA 1484 after monotonic tensile testing: $21^{\circ} \mathrm{C}, \varepsilon_{\mathrm{in}}=0.672 \%$.

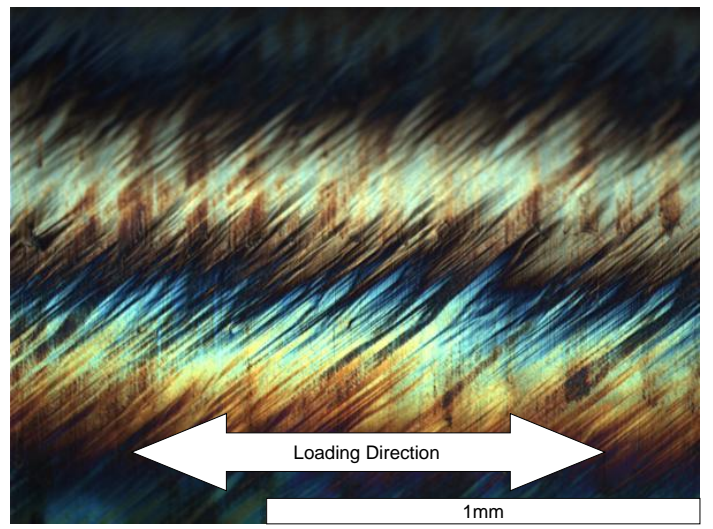

Figure 8: Slip bands intersecting surface of PWA 1484 after monotonic tensile testing: $650^{\circ} \mathrm{C}, \varepsilon_{\mathrm{in}}=0.757 \%$.

Test results indicate that PWA 1484 experiences a transition in deformation response between $545^{\circ} \mathrm{C}$ and $650^{\circ} \mathrm{C}$. This observation is in line with that found for the first generation $\mathrm{Ni}$ base superalloy PWA 1480 [12]. As this study is interested in the interactions between low(er)-temperature inelastic deformation and high(er)-temperature material degradation, slip band spacing was characterized between $21^{\circ} \mathrm{C}$ and $545^{\circ} \mathrm{C}$ only. Slip band spacing can be related to the inelastic strain range, $\Delta \varepsilon_{i n}$, absolute temperature, $T$, and number of cycles, $N$, by [17]

$$
C=D \Delta \varepsilon_{\text {in }}^{-m} \exp \left(\frac{Q_{s l}}{R T}\right) N^{a}
$$

where $D, m$ and $a$ are constants, $Q_{s l}$ is the activation energy for slip, and $R$ is the universal gas constant. To account for single crystal anisotropy, a critical plane approach is taken in which the inelastic strain range is replaced by the inelastic shear strain range on the slip system having the highest Schmid factor, $\Delta \gamma_{i n}^{s l}$. Making this substitution in Eq. 4, substituting $X_{\gamma}^{0}$ for $X_{\text {crit }}$, inserting Eqs. 3 and 4 into Eq. 2 and solving for the number of cycles yields

$$
N_{i}=\left[B\left(\Delta \gamma_{i n}^{s l}\right)^{-m} \exp \left(\frac{Q_{\gamma^{\prime}}+Q_{s l}}{R T_{e f f}}\right) t^{n}\right]^{b}
$$

where the temperature has been replaced with the cycle effective temperature defined in Eq. $1, B$ and $b$ are combined parameters and all other variables are defined above. The model was calibrated to all of the baseline test results in Table 2 by fitting of $B$, and $b$. Model correlations versus experimental results are provided in Fig. 9. 
Table II: Mechanical test matrix

Baseline Fatigue Tests

\begin{tabular}{|c|c|c|c|c|c|c|c|c|c|c|c|c|}
\hline Waveform & Orientation & $\mathrm{R}$ & $\begin{array}{l}\text { Hold time } \\
\text { (s) }\end{array}$ & $\begin{array}{c}\Delta \varepsilon(\text { mech }) \\
(-)\end{array}$ & $\begin{array}{c}\varepsilon_{\mathrm{a}}(\text { mech }) \\
(-)\end{array}$ & $\begin{array}{c}\Delta \varepsilon(\text { in }) @ ~ N i / 2 \\
(-)\end{array}$ & $\begin{array}{c}\mathrm{Ni} / 2 \\
\text { (cycle) }\end{array}$ & $\begin{array}{c}\mathrm{Ni} \\
\text { (cycle) }\end{array}$ & $\begin{array}{c}\mathrm{Nf} \\
\text { (cycle) }\end{array}$ & $\begin{array}{c}\text { Tmin } \\
(\operatorname{deg} C)\end{array}$ & $\begin{array}{c}\operatorname{Tmax} \\
(\operatorname{deg} C)\end{array}$ & $\begin{array}{c}\text { Teff } \\
\text { (deg C) }\end{array}$ \\
\hline OP-TMF* & 001 & -0.9 & 0 & 0.013 & 0.0065 & 0.003517 & 54 & 107 & 116 & 550 & 1050 & 953 \\
\hline OP-TMF* & 001 & -0.9 & 0 & 0.009 & 0.0045 & 0.000869 & 236 & 471 & 560 & 550 & 1050 & 953 \\
\hline OP-TMF* & 001 & -1.0 & 0 & 0.005 & 0.0025 & 0.000065 & 905 & 1810 & 2409 & 550 & 1050 & 953 \\
\hline $\mathrm{OP}-\mathrm{BiF}^{*}$ & 001 & -0.8 & 0 & 0.013 & 0.0065 & 0.002944 & 38 & 76 & 119 & 550 & 1050 & 1002 \\
\hline $\mathrm{OP}-\mathrm{BiF}^{*}$ & 001 & -0.9 & 0 & 0.009 & 0.0045 & 0.000179 & 185 & 370 & 408 & 550 & 1050 & 1002 \\
\hline OP-BiF* & 001 & -1.0 & 0 & 0.007 & 0.0035 & 0.000096 & 211 & 421 & 956 & 550 & 1050 & 1002 \\
\hline
\end{tabular}

Supporting Fatigue Tests

\begin{tabular}{|c|c|c|c|c|c|c|c|c|c|c|c|c|}
\hline Waveform & Orientation & $\mathrm{R}$ & $\begin{array}{l}\text { Hold time } \\
\text { (s) }\end{array}$ & $\begin{array}{c}\Delta \varepsilon(\text { mech }) \\
(-)\end{array}$ & $\begin{array}{c}\varepsilon_{\mathrm{a}}(\text { mech }) \\
(-)\end{array}$ & $\begin{array}{c}\Delta \varepsilon \text { (in) @ Ni/2 } \\
(-)\end{array}$ & $\begin{array}{c}\mathrm{Ni} / 2 \\
\text { (cycle) }\end{array}$ & $\begin{array}{c}\mathrm{Ni} \\
\text { (cycle) }\end{array}$ & $\begin{array}{c}\mathrm{Nf} \\
\text { (cycle) }\end{array}$ & $\begin{array}{c}\text { Tmin } \\
(\operatorname{deg} C)\end{array}$ & $\begin{array}{c}\text { Tmax } \\
(\operatorname{deg} C)\end{array}$ & $\begin{array}{c}\text { Teff } \\
\text { (deg C) }\end{array}$ \\
\hline OP-TMF & 001 & -0.4 & 0 & 0.013 & 0.0065 & 0.003076 & 45 & 89 & 110 & 550 & 1050 & 953 \\
\hline OP-TMF & 001 & 0.0 & 0 & 0.009 & 0.0045 & 0.000567 & 280 & 560 & 781 & 550 & 1050 & 953 \\
\hline OP-TMF & 001 & -1.0 & 0 & 0.013 & 0.0065 & 0.002411 & 231 & 461 & 584 & 550 & 1050 & 953 \\
\hline OP-TMF & 001 & -1.0 & 0 & 0.009 & 0.0045 & 0.000725 & 305 & 610 & 1012 & 550 & 1050 & 953 \\
\hline OP-TMF & 001 & -0.6 & 300-HT & 0.013 & 0.0065 & 0.000577 & 32 & 64 & 71 & 550 & 1050 & 1027 \\
\hline OP-BiF & 001 & -0.9 & 0 & 0.01216 & 0.00608 & 0.001247 & 42 & 84 & 118 & 550 & 1050 & 1002 \\
\hline OP-BiF & 001 & -0.8 & 0 & 0.0106 & 0.0053 & 0.001162 & 59 & 117 & - & 550 & 1050 & 1002 \\
\hline OP-BiF* & 001 & -1.0 & 300-HT & 0.007 & 0.0035 & 0.000100 & - & 230 & - & 550 & 1050 & 1032 \\
\hline OP-BiF* & 001 & -1.0 & 300-HT & 0.009 & 0.0045 & 0.002680 & 42 & 83 & 101 & 550 & 1050 & 1032 \\
\hline OP-BiF* & 001 & -1.0 & 300-HT & 0.013 & 0.0065 & 0.004417 & 36 & 71 & 77 & 550 & 1050 & 1032 \\
\hline OP-BiF & 001 & -1.0 & 0 & 0.009 & 0.0045 & 0.000099 & 1874 & 3748 & 7423 & 550 & 900 & 865 \\
\hline
\end{tabular}

Off-Axis Fatigue Tests

\begin{tabular}{|c|c|c|c|c|c|c|c|c|c|c|c|c|}
\hline Waveform & Orientation & $\mathrm{R}$ & $\begin{array}{l}\text { Hold time } \\
\text { (s) }\end{array}$ & $\begin{array}{c}\Delta \varepsilon(\text { mech }) \\
(-)\end{array}$ & $\begin{array}{c}\varepsilon_{\mathrm{a}}(\mathrm{mech}) \\
(-)\end{array}$ & $\begin{array}{c}\Delta \varepsilon(\text { in }) @ \mathrm{Ni} / 2 \\
(-)\end{array}$ & $\begin{array}{c}\mathrm{Ni} / 2 \\
\text { (cycle) }\end{array}$ & $\begin{array}{c}\mathrm{Ni} \\
\text { (cycle) }\end{array}$ & $\begin{array}{c}\mathrm{Nf} \\
\text { (cycle) }\end{array}$ & $\begin{array}{c}\text { Tmin } \\
(\operatorname{deg} C)\end{array}$ & $\begin{array}{c}\text { Tmax } \\
(\operatorname{deg} C)\end{array}$ & $\begin{array}{c}\text { Teff } \\
\text { (deg C) }\end{array}$ \\
\hline OP-TMF & 111 & -1.0 & 0 & 0.005 & 0.0025 & 0.000702 & 124 & 247 & 309 & 550 & 1050 & 953 \\
\hline OP-TMF & 111 & -1.0 & 0 & 0.009 & 0.0045 & 0.003246 & 16 & 31 & 52 & 550 & 1050 & 953 \\
\hline OP-TMF & 111 & -1.0 & 0 & 0.013 & 0.0065 & 0.006656 & 11 & 22 & 27 & 550 & 1050 & 953 \\
\hline OP-TMF & $\sim 123$ & -0.9 & 0 & 0.005 & 0.0025 & 0.000628 & 283 & 565 & 619 & 550 & 1050 & 953 \\
\hline OP-TMF & $\sim 123$ & -1.0 & 0 & 0.007 & 0.0035 & 0.001741 & 111 & 223 & 379 & 550 & 1050 & 953 \\
\hline OP-TMF & $\sim 123$ & -1.0 & 0 & 0.009 & 0.0045 & 0.003710 & 24 & 48 & 107 & 550 & 1050 & 953 \\
\hline
\end{tabular}

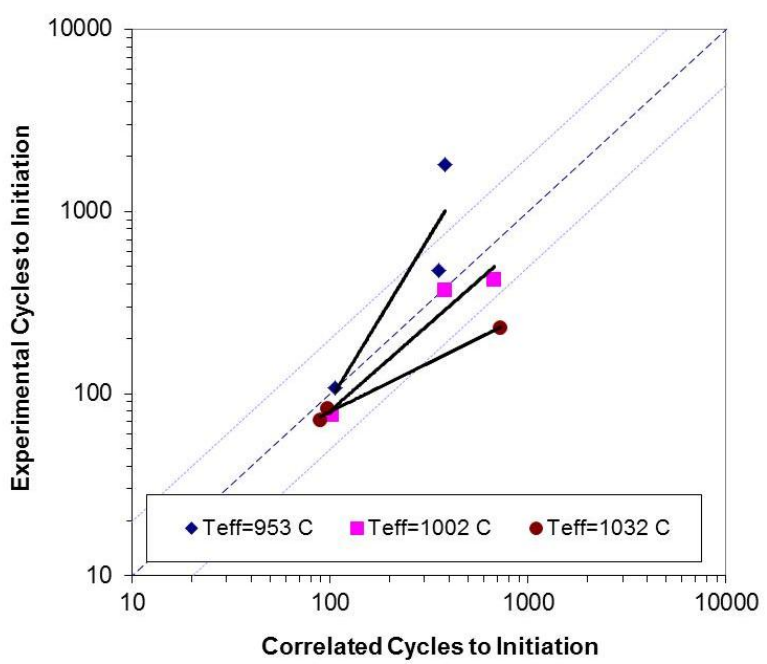

Figure 9: Correlated model (Eq. 5) results using all baseline test results. Test results delineated by effective temperature

Given that Eq. 5 does not collapse the correlated test results to a single trend as a function of temperature, one might assume that the model is not accurately capturing the interactions between the low-temperature plasticity and the high-temperature material degradation. This is relatively easy to address by explicitly accounting for slip-microstructural evolution interactions. Specifically, given that superalloys exhibit planar slip, an existing slip system may be affected by diffusing oxygen and alloy constituents, or evolving second phase particles. Capturing the interactions between the dislocation motion and material evolution is key to producing an effective OP TMF life model. Microscopy of the tested specimens indicates that the inelastic deformation-high temperature degradation interaction occurs in OP TMF by one of four ways. First, high-temperature degradation may occur as a precursor to plastic deformation, as shown in Fig. 10a. Figure 10a depicts an oxide spike occurring along an oxidized slip plane. Given that oxidation is occurring on the slip plane in front of the oxide spike, one can assume that the oxidized slip plane has enabled the subsequent growth of the oxide spike. Furthermore, multiple parallel slip planes in the photo are oxidized. Crack branching from the oxide spike occurs on crystallographic planes roughly parallel to the fracture surface shown in the right of the figure. Additionally, environmental degradation may occur independent of inelastic deformation. As an example, oxidation may occur along interdendritic regions, as shown in Fig. 10b. Figure 10b shows oxide spikes originating from the free surface and propagating along interdendritic boundaries. Given that the interdendritic regions are the primary "faults" in single crystal Ni-base superalloys, an oxide spike occurring in this region is more likely to become a terminal crack then if it had occurred in the base material. The third type of deformation-high temperature interaction that may occur during OP TMF is inelastic deformation interacting with a region of the material which has preexisting environmental degradation. This situation is depicted in Figs. 11 and 12. Figures 11 and 12 show slip bands impinging upon an existing oxide spike. This sequence 
of events has the obvious result of aiding an oxide spike in becoming a crack. It is this particular series of events that Eq. 5 is intended to capture. The final damage mechanism interaction occurs when a crack exists first, and $\gamma^{\prime}$ depletion occurs as a result of the freshly created surface, as shown in Fig. 13. Figure 13a shows an oxide spike with crack branching surrounded by $\gamma$ ' depleted material, whereas Fig. 13b shows multiple surface cracks

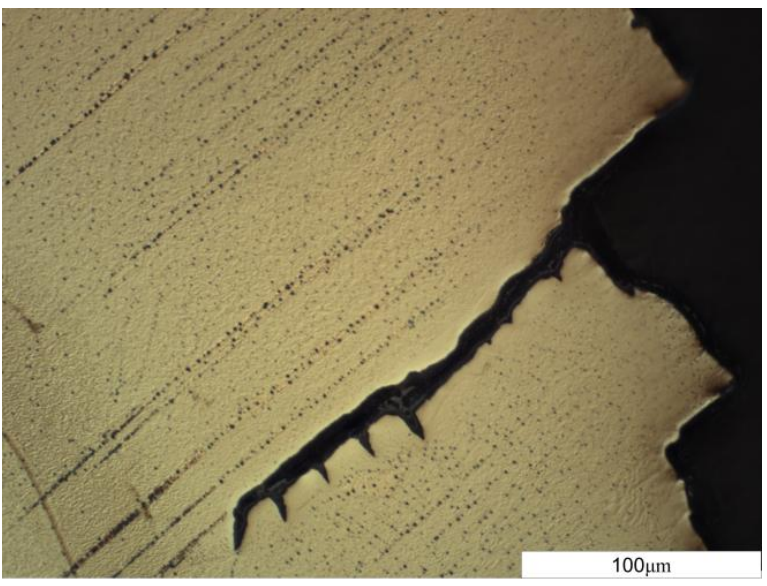

a) surrounded by $\gamma^{\prime}$ depleted material. In both cases the fatigueenvironment interactions occur in a way as to reinforce each other, i.e., the aluminum from the $\gamma^{\prime}$ enables the oxide spike growth to continue as well as provides a brittle oxidized surface on the fatigue crack enabling subsequent crack growth.

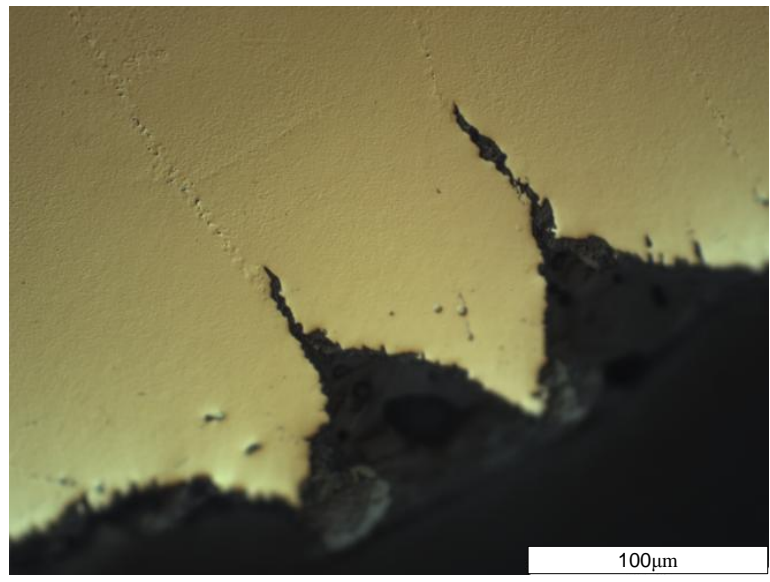

b)

Figure 10: a) Specimen cross section near free surface. $0.9 \%$ mechanical strain range OP TMF, b) Specimen cross sections near free surface. $1.3 \%$ mechanical strain range OP BiF. Horizontal loading direction
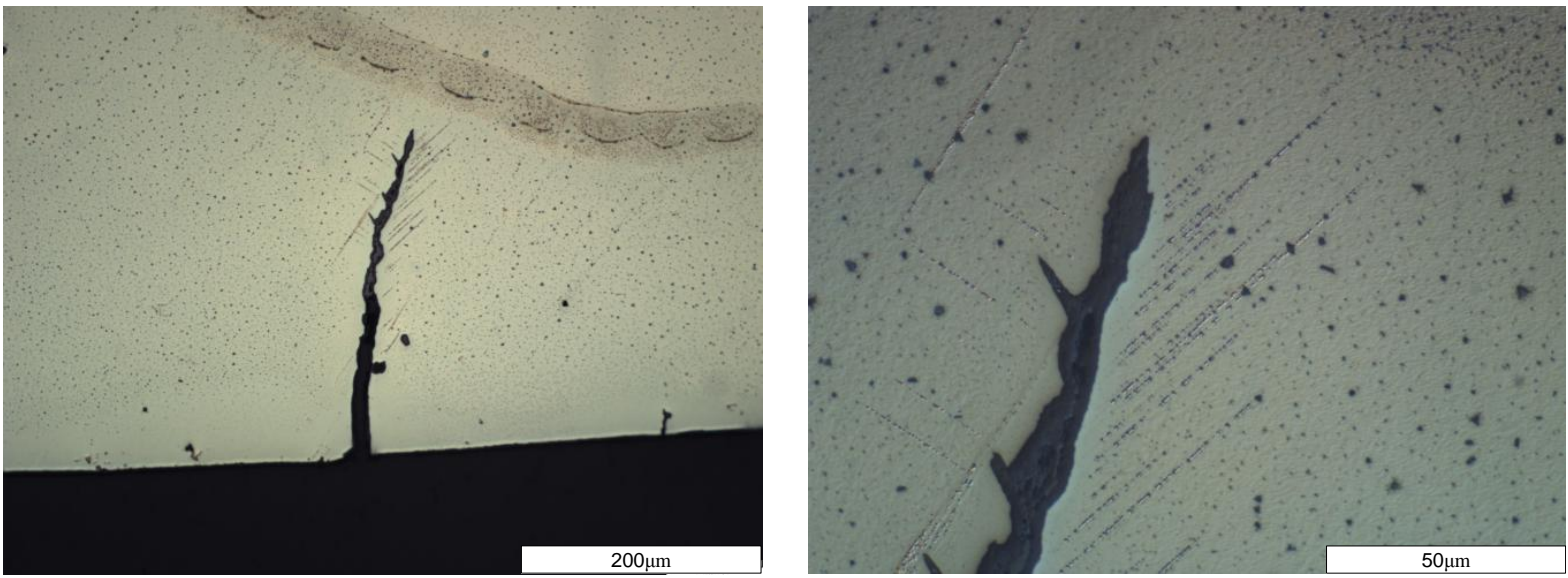

Figure 11: Specimen cross sections near free surface: $0.9 \%$ mechanical strain range OP TMF. Horizontal loading direction 

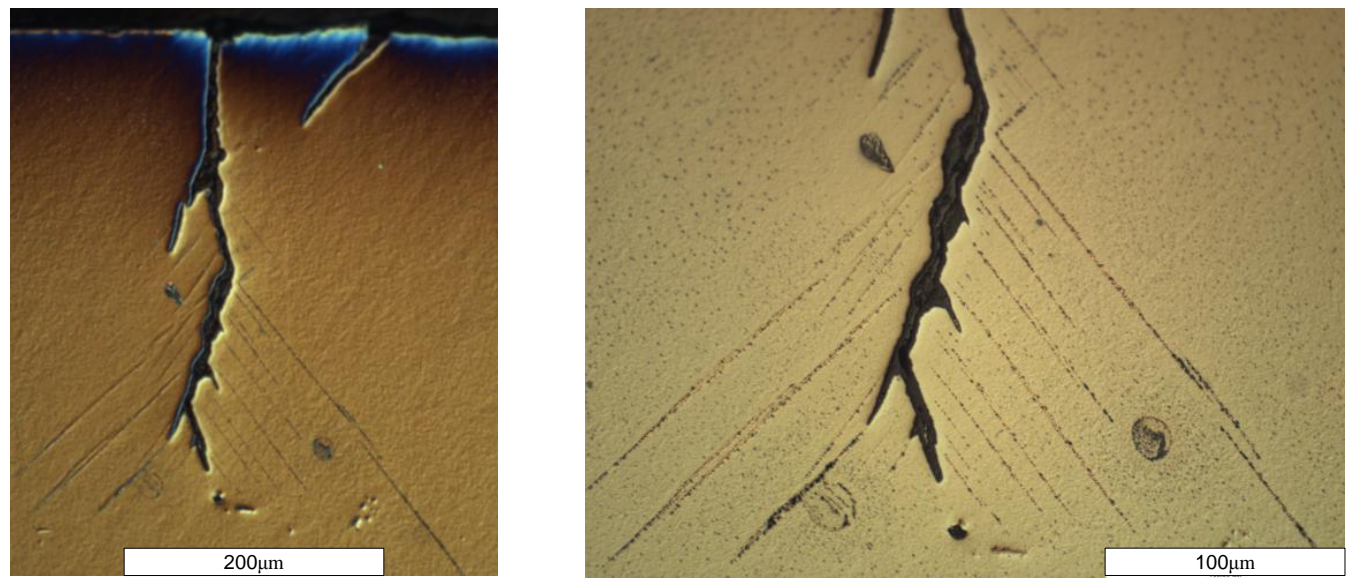

Figure 12: Specimen cross sections near free surface: $0.9 \%$ mechanical strain range OP TMF. Horizontal loading direction

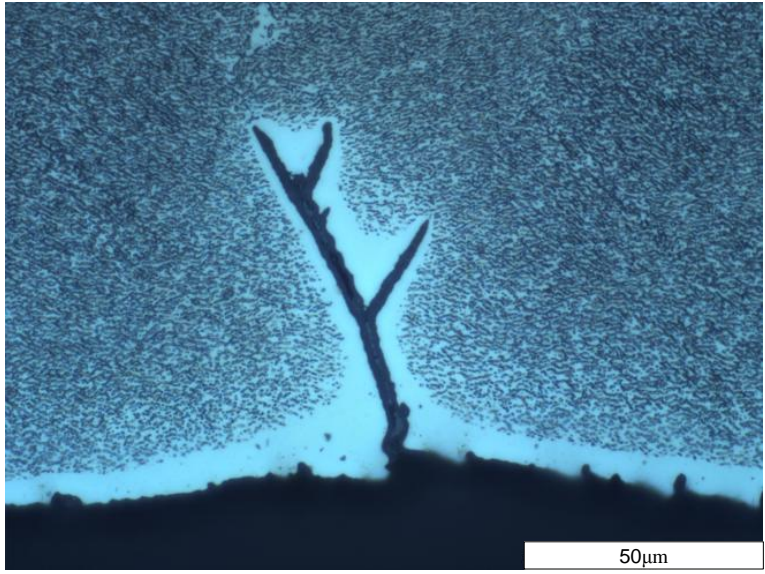

a)

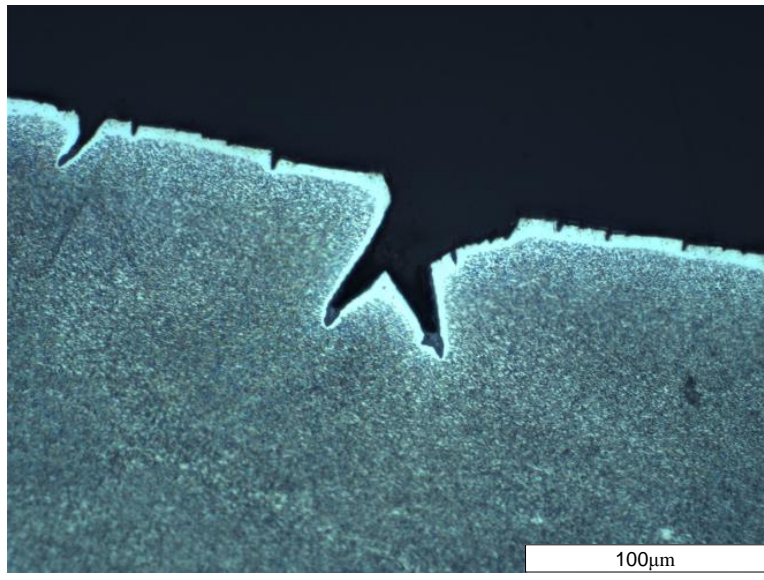

b)

Figure 13: 1.3\% mechanical strain range OP TMF, <001> loading orientation, 5 minute high temperature hold. Horizontal loading direction

Given all of the environmental-fatigue interactions occurring during OP TMF, one can imagine that modeling the interactions as a simple superposition of the independent damage mechanisms would not fully capture the synergy resulting from their simultaneous occurrence.

The conclusions drawn from the above discussion and the accompanying microscopy are as follows:

1. All of the OP TMF specimens tested exhibit minimal non-terminal surface cracks in and around the gage section, relative to $\mathrm{BiF}$ specimens tested under similar conditions. This observation indicates that the OP TMF specimens primarily experienced fatigue-dominated damage mechanisms.

2. All of the $\mathrm{OP} \mathrm{BiF}$ specimens tested exhibit a considerable number of surface cracks accompanied by crack surface oxidation and subsurface $\gamma^{\prime}$ depletion, indicating a considerable amount of environmentalfatigue damage mechanism interaction.

3. Enhanced diffusion of oxygen appears to occur along slip planes and interdendritic boundaries, as indicated in Fig. 10.
4. Cracks initiate by the interaction of slip bands impinging upon an oxide spike, or some other environmentally degraded portion of the material, as shown in Figs. 11 and 12.

A life prediction model intended to capture the interaction between lower temperature deformation and higher temperature material degradation must account for the effect of oxidation on accumulated inelastic deformation, regardless of the order in which the two occur. The functional form of Eq. 5 was used as a starting point for developing a physics-inspired life prediction model intended to capture these interactions. In doing so, the stress assisted $\gamma^{\prime}$ depletion of PWA 1484 could be described by the following expression [17]:

$X_{\gamma^{\prime}}^{\text {stressed }}=X_{\gamma^{\prime}}^{0} k \exp \left(\frac{\overline{\bar{v}}\left|\tau_{T \max }\right|}{R T_{\text {eff }}}\right)$

Equation 6 correlates the per-cycle stress assisted $\gamma^{\prime}$ depletion with the non-stressed $\gamma^{\prime}$ depletion, as defined by Eq. 2 . The other terms of the equation are: a constant, $k$; the shear stress occurring 
at maximum temperature, $\tau_{T_{\max }}$; the experimentally determined volume over which the stress acts, $\bar{V}$; and the TMF cycle effective temperature, $T_{e f f}$, as defined by Eq. 1 . Equation 6 effectively couples the interaction between the $\mathrm{Al}$ diffusion (which results in $\gamma^{\prime}$ depletion and oxidation) and the shear stress aiding dislocation motion. Upon exiting the material surface, the shear driven dislocations create fresh surface area on which subsequent oxygen diffusion may occur. Interestingly the stress-assisted $\gamma^{\prime}$ depletion was not found to be strongly correlated to the hydrostatic portion of the applied stress, as discussed in [17].

The coupling between low(er)-temperature inelastic deformation and thermally activated material processes (including secondphase particle evolution) was found to be described by [17]

$$
C=\frac{r_{0}\left(\Delta \gamma_{i n}^{s l}\right)^{-m}}{h \exp \left(u T_{e f f}\right) t^{1 / 3}} \exp \left(\frac{Q_{s l}+Q_{\gamma^{\prime}}-\bar{V} \sigma_{T_{\min }}}{R T_{e f f}}\right) N^{a}
$$

Equation 7 incorporates the experimentally determined secondphase particle coarsening kinetics proposed elsewhere [26]

$$
\frac{r_{0}}{h \exp \left(u T_{\text {eff }}\right) t^{1 / 3}}
$$

as a means of modifying the slip spacing due to dislocation pinning event ( $\gamma$ ' particle) evolution. Equation 7 also suggests an explicit connection between the $\gamma^{\prime}$ depletion kinetics via the inclusion of $Q_{\gamma \prime}$. As such, the relationship effectively couples the inelastic deformation occurring at lower temperatures and the material evolution $\left(\gamma^{\prime}\right.$ particle coarsening, aluminum diffusion, oxygen diffusion) occurring as a result of high temperature service. The remaining variables in Eq. 7 are defined as follows: $h$ and $u$ are constants, $r_{0}$ is the initial side length of the $\gamma^{\prime}$ particles, $t$ is the time during which the material experiences temperatures over $800^{\circ} \mathrm{C}, \sigma_{\mathrm{T}_{\min }}$ is the stress at cycle minimum temperature, and all other variables are defined above. The final life equation is then:

$N=\left[\frac{H r_{0}\left(\Delta \gamma_{i n}^{s l}\right)^{-m}}{\exp \left(u T_{\text {eff }}\right) t^{1 / 3}} \exp \left(\frac{Q_{s l}+2 Q_{\gamma^{\prime}}-\bar{V}\left(\sigma_{T_{\min }}+\left|\tau_{T_{\max }}\right|\right)}{R T_{\text {eff }}}\right) t^{-n}\right]^{p}$ where, again, $H, u$ and $p$ are constants. The life model in Eq. 9 explicitly couples the environmental-fatigue mechanism interactions found to occur during OP TMF and shown in Figs. 10 through 13. Specifically, the model incorporates stress-assisted oxidation, temperature-dependent inelastic deformation evolution as well as material evolution through the inclusion of $\gamma$ ' coarsening. Only through full accounting of material evolutiondeformation-environmental interactions will a life prediction model provide sufficient insight and be capable of accurate life prediction outside of the bounds provided by the calibration studies. The model was calibrated to the nine baseline tests shown in Table 2 (denoted with *) by fitting the three constants $H$, $u$ and $p$. Values for all of the constants in Eq. 9 are provided in Table 3, and model correlations versus experimental results for the nine baseline tests are shown in Fig. 14. Model predictions for all TMF and $\mathrm{BiF}$ tests are shown in Figure 15.

Table III: Parameter values determined by calibration to baseline tests. Value of $r_{0}$ from [10]

\begin{tabular}{|c|c|c|}
\hline $\mathrm{A}$ & $1.00 \times 10^{15}$ & $(-)$ \\
\hline $\mathrm{r}_{0}$ & 300 & $\mathrm{~nm}$ \\
\hline $\mathrm{u}$ & 0.04 & $1 / \mathrm{K}$ \\
\hline $\mathrm{m}$ & 1.29 & $(-)$ \\
\hline $\mathrm{Q}_{\mathrm{sl}}$ & 6056 & $\mathrm{~J} / \mathrm{mol}$ \\
\hline $\mathrm{Q}_{\mathrm{ox}}$ & 162863 & $\mathrm{~J} / \mathrm{mol}$ \\
\hline $\mathrm{B}$ & 161 & $\mathrm{~m}^{3} / \mathrm{mol}$ \\
\hline $\mathrm{n}$ & $\mathrm{f}(\mathrm{temp})$ & $(-)$ \\
\hline $\mathrm{d}$ & 0.17 & $(-)$ \\
\hline $\mathrm{Ra}$ & 197 & $\mathrm{~nm}$ \\
\hline $\mathrm{h}$ & 0.2 & $(-)$ \\
\hline $\mathrm{p}$ & 0.27 & $(-)$ \\
\hline
\end{tabular}

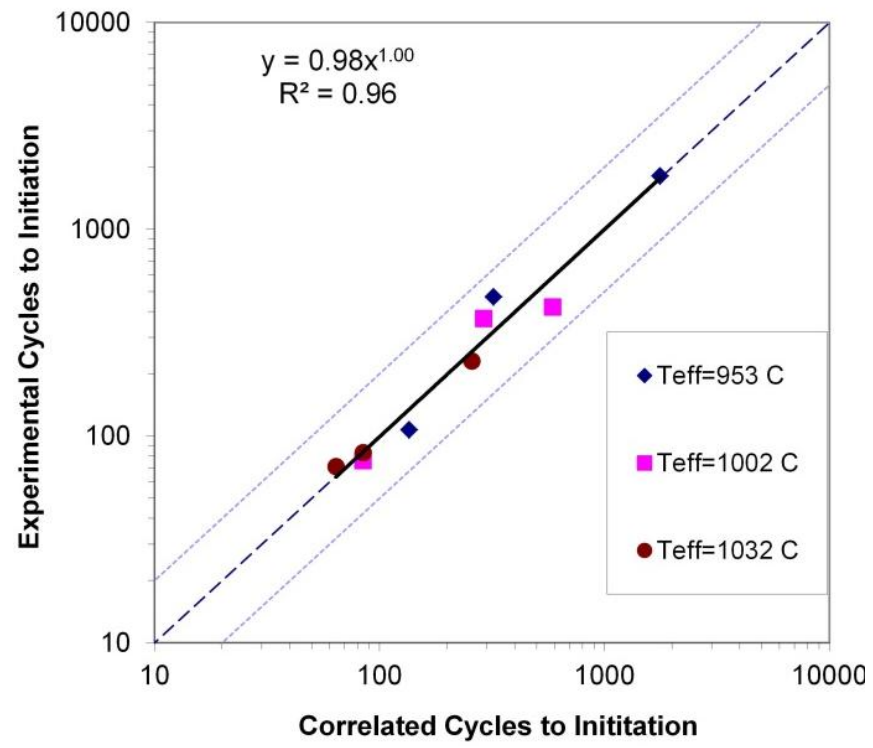

Figure 14: Model correlations after calibration to nine baseline tests 


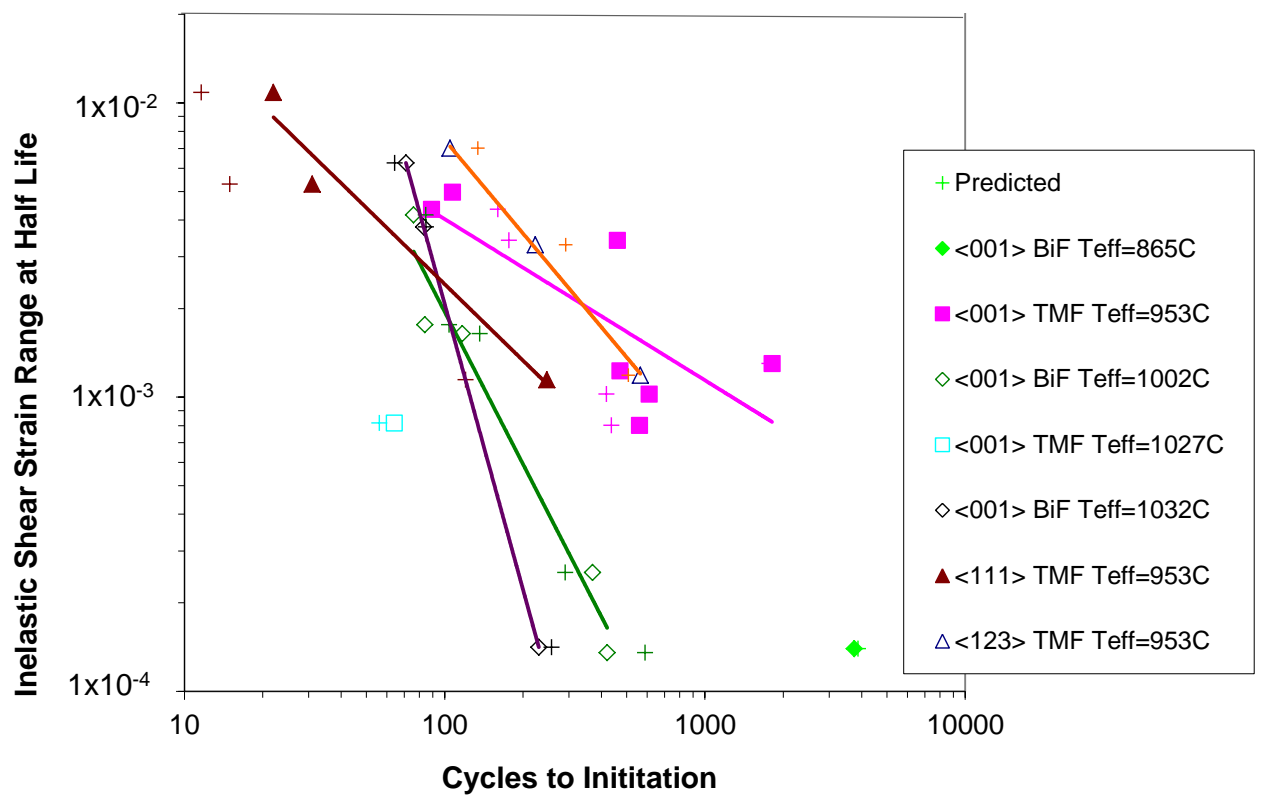

Figure 15: Out-of-phase TMF and BiF test results and model predictions delineated by specimen orientation, cycle type and effective temperature

The model does an excellent job of predicting OP TMF and BiF tests results as a function of primary loading orientation, cycle type and temperature, hold time and applied load with $94 \%$ of the predictions falling within a factor of 2 of the experimental results and provides a methodology for TMF life prediction over a wide range of imposed conditions. Though it was required to first determine the dominant damage mechanisms occurring and to characterize their interactions, ultimately, the implementation of these interactions into a physics-based formulation provides the life model with its predictive efficacy. Future work utilizing this model includes application of high-cycle fatigue superimposed upon TMF cycles as well as incorporation of multiaxial loading and notched component analysis.

\section{Conclusions}

The primary conclusions from this work are as follows;

- OP TMF damage is dominated by fatigue and environmental-fatigue damage mechanisms, depending upon test conditions.

- $\mathrm{OP} \mathrm{BiF}$ damage is dominated by environmental-fatigue damage mechanisms.

- $\quad$ Crack initiation in OP TMF and BiF results from slip band-environmental interactions. Specifically, the microscopy provided documents crack initiation from slip band-oxide spike interactions.

- The inelastic deformation occurring during OP TMF is a result of a complex interaction between lowertemperature slip and higher-temperature material evolution.

- A life model is provided which explicitly couples the deformation-environmental interactions as well as material evolution. The model predicts cycles to crack initiation as a function of applied load, primary loading orientation, cycle time, temperatures and hold times.
The model performs well, with $94 \%$ of the predictions being within a factor of 2 of the experimental results.

- Use of a temperature based on an Arrhenius averaging technique, denoted as the effective temperature, has been shown to be a useful way in which to account for temperature effects.

- This study demonstrates the inherent power of applying a broadly integrated range of fundamental studies and capabilities for life prediction under complex loading and thermal conditions.

\section{Acknowledgement}

The authors would like to thank Raymond Kersey at Pratt \& Whitney for his technical support of this work. Financial support for this work was provided by Pratt \& Whitney, East Hartforrd, CT. They would also like to acknowledge contributions by Mr. Max Kaulbach who, as a part of his NSF REU project, assisted with some of the measurements of slip band spacing.

\section{References}

1. Erickson, G.L. Ni-Based Superalloy Developments. 1993. Warrendale, PA, USA: Publ by Minerals, Metals $\&$ Materials Soc (TMS).

2. Oesterle, W., Bettge, D., Fedelich, B., Klingelhoeffer, H., Modelling the Orientation and Direction Dependence of the Critical Resolved Shear Stress of Nickel-Base Superalloy Single Crystals. Acta Materialia, 2000. 48(3): p. 689-700.

3. Arakere, N.K., Orozco, E., Analysis of Low Cycle Fatigue Properties of Single Crystal Nickel-Base Turbine Blade Superalloys. High Temperature Materials and Processes, 2001. 20(5-6): p. 403-419. 
4. Okazaki, M., Sakaguchi, M., Thermo-Mechanical Fatigue Failure of a Single Crystal Ni-Based Superalloy. International Journal of Fatigue, 2008. 30(2): p. 318-323.

5. Neu, R.W., Sehitoglu, H., Thermomechanical fatigue, oxidation, and creep. Part I. Damage mechanisms. Metallurgical transactions. A, Physical metallurgy and materials science, 1989. 20 A(9): p. 1755-1767.

6. Sehitoglu, H., Boismier, D. A., Thermo-mechanical fatigue of Mar-M247. Part 2. Life prediction. Journal of Engineering Materials and Technology, Transactions of the ASME, 1990. 112(1): p. 80-89.

7. Miller, M.P., McDowell, D. L., Oehmke, R. L. T., A Creep-Fatigue-Oxidation Microcrack Propagation Model for Thermomechanical Fatigue. Journal of Engineering Materials and Technology, 1992. 114(3): p. 282-288.

8. Amaro, R.L., Antolovich, S. D., Neu, R. W. FernandezZelaia, P., Hardin, W. G., Thermomechanical Fatigue and Bithermal-Thermomechanical Fatigue of a NickelBase Single Crystal Superalloy. International Journal of Fatigue- In Press, 2010.

9. Amaro, R.L., Antolovich, S. D., Neu, R. W., Mechanism-Based Life Model for Out-of-Phase Thermomechanical Fatigue in Single Crystal Ni-base Superalloys. Fatigue \& Fracture of Engineering Materials \& Structures, In Press, 2011.

10. Cetel, A.D., Duhl, D.N., Second Generation NickelBase Single Crystal Superalloy. Superalloys, 1988: p. 235-244.

11. Reed, R.C., The superalloys : fundamentals and applications. 2008, Cambridge: Cambridge University Press.

12. Gayda, J., Gabb, T., P., Miner, R., V., Halford, G., R.,, Bithermal Low-Cycle Fatigue Behavior of a NiCoCrAlY-Coated Single Crystal Superalloy. 1987, NASA Technical Memorandum 89831: NASA Glenn Ressearch Center. p. 25.

13. Gayda, J., Gabb, T. P., Miner, R. V., Halford, G. R., Isothermal and "Bithermal" Thermomechanical Fatigue Behavior of a NiCoCrAlY-Coated Single Crystal Superalloy, in Superalloys 1988, S. Reichman, Duhl, D., N., Maurer, G., Antolovich, S., D., Lund, C., Editor. 1988, The Metallurgical Society. p. 575-584.

14. Halford, G.R., MCGaw, M. A., Bill, R. C., Fanti, P. D., Bithermal Fatigue: A link Between Isothermal and Thermomechanical Fatigue. ASTM STP 942, ed. H.D. Solomon. 1987: ASTM STP 942. Low cycle fatigue: A Symposium.

15. Verrilli, M.J., Bithermal Fatigue of a Nickel-Base Superalloy Single Crystal. 1988, NASA Technical Memorandum 100885: Cleveland, Ohio. p. 13.

16. ASTM Standard E 606-04 E1 "Standard Practice for Strain-Controlled Fatigue Testing". 2004: West Conshohocken, PA.

17. Amaro, R.L., Thermomechanical Fatigue Crack Formation in a Single Crystal Ni-base Superalloy, in Mechanical Engineering. 2010, Georgia Institute of Technology: Atlanta. p. 321.

18. Dumoulin, S., Busso, E. P., O'Dowd, N. P., Allen, D. A Multiscale Approach for Coupled Phenomena in FCC Materials at High Temperatures. 2003: Taylor and Francis Ltd.
19. Kupkovits, R., Thermomechanical Fatigue Behavior of the Directionally-Solidified Nickel-Base Superalloy CM247LC, in Mechanical Engineering. 2009, Georgia Institute of Technology: Atlanta, Ga.

20. Zhao, L.G., O'Dowd, N. P., Busso, E. P., A coupled kinetic-constitutive approach to the study of high temperature crack initiation in single crystal nickelbase superalloys. Journal of the Mechanics and Physics of Solids, 2006. 54(2): p. 288-309.

21. Bouhanek, K., Oquab, D., Pieraggi, B., High temperature oxidation of single-crystal Ni-base superalloys. Materials Science Forum, 1997. 251254(part 1): p. 33-40.

22. Li, M.H., Sun, X. F., Li, J. G., Zhang, Z. Y., Jin, T., Guan, H. R., Hu, Z. Q., Oxidation behavior of a singlecrystal Ni-base superalloy in air. I. At 800 and 900C. Oxidation of Metals, 2003. 59(5-6): p. 591-605.

23. Göbel, M., A. Rahmel, and M. Schütze, The isothermaloxidation behavior of several nickel-base single-crystal superalloys with and without coatings. Oxidation of Metals, 1993. 39(3): p. 231-261.

24. Gross, M., Goitia Bigord ̃̃, J., Kolarik, V., Engel, W., Oxidation of the turbine blade material CMSX4 studied by X-ray diffraction. J. Phys. IV France, 1998. 08(PR5): p. Pr5-505-Pr5-510.

25. Antolovich, S.D., Baur, R., Liu, S., A Mechanistically Based Model for High Temperature LCF of Ni Base Superalloys, in Superalloys 1980, J.K. Tien, Wlodek, S. T., Morrow, H., Gell, M., Mauer, G. E., Editor. 1980, The Metallurgical Society. p. 605-613.

26. Manonukul, A., Dunne, F. P. E., Knowles, D. Physically-based model for creep in nickel-base superalloy C263 both above and below the gamma solvus. Acta Materialia, 2002. 50(11): p. 2917-2931. 